\title{
Panamericanismo y negocios binacionales. Transportes, carreteras y servicios turísticos (Estados Unidos de América y México, 1920-1940)
}

\author{
Panamericanism and Binational Business. \\ Transportation, Highways, and Touristic \\ Services (USA and Mexico, 1920-1940)
}

\author{
Luis Anaya Merchant \\ (D) https://orcid.org/0000-0002-4595-1921 \\ Universidad Autónoma del Estado de Morelos, México. \\ luisanay@hotmail.com
}

Resumen: Este trabajo explora la convergencia de intereses estatales y privados binacionales en la temprana construcción de carreteras mexicanas. Otro objetivo es comparar la evolución del autotransporte en Estados Unidos y México; el ejercicio se justifica porque aclara apoyos estadunidenses, por sus impactos y porque muestra cercanías diplomáticas de dos países con historias confrontadas. La cooperación se animó por el Panamericanismo y el New Deal porque crearon ambientes diplomáticamente favorables. Entre las industrias beneficiadas por las nuevas redes carreteras destacamos los servicios turísticos. El trabajo también registra obstáculos y costos históricos asociados con políticas erráticas. Las consecuencias de la competencia entre

Cómo citAR: Anaya Merchant, L. (2021). Panamericanismo y negocios binacionales. Transportes, carreteras y servicios turísticos (Estados Unidos de América y México, 1920-1940). Secuencia (110), e1801. DOI: https://doi.org/10.18234/secuencia.v0i110.1801

c) 9

Esta obra está protegida bajo una Licencia Creative Commons Atribución-NoComercial 4.0 Internacional. 
automotores y ferrocarriles en ambos países es otro objeto de comparación y estudio. Estados Unidos y México impulsaron campañas de propaganda favorables a atracciones turísticas mexicanas cuyo destino también se explora en el trabajo.

Palabras clave: paralelismo; panamericana; industria; turismo; automotores.

Abstract: This paper explores the convergence of binational state and private interests in the early construction of Mexican highways. Another objective of the study is to compare the evolution of motor transport in the United States and Mexico; the exercise is justified by clarifying American support for its different impacts and for analyzing a moment of diplomatic closeness in two countries of confronted stories. The cooperation was encouraged by Pan Americanism and New Deal because they created diplomatically favorable environments. Among the industries benefiting from the new road networks, we highlight the tourism services. Work also records historical obstacles and costs associated with erratic policies. The consequences of the competition between auto motors and railroads in both countries are another object of comparison and study. The United States and Mexico promoted propaganda campaigns favorable to Mexican tourist attractions whose fate is also explored at work.

Keywords: Paralelism; panamerican highway; industry; tourism; automotors.

Recibido: 22 de octubre de 2019 Aceptado: 27 de mayo de 2020

Publicado: 10 de mayo de 2021

\section{INTRODUCCIÓN}

T a sociedad mexicana adaptó e impulsó mercados e industrias relativaLmente nuevos durante su "reconstrucción posrevolucionaria" en la década de los veinte. Un caso paradigmático de esta adaptación y adopción lo ofrecían las nuevas posibilidades de transportación terrestre: los vehículos automotores, importados fundamentalmente desde Estados Unidos. Sus potencialidades se combinarían con los ferrocarriles, aunque también los 
contrastarían pues su competencia terminaría acelerando su declinación. No obstante, durante las décadas de los veinte y treinta los ferrocarriles, los autos y los incipientes acuerdos de navegación continuaban alentando mayores posibilidades comunicativas y también nuevas industrias. El interés de este ensayo es mostrar la articulación de intereses particulares y estatales binacionales en la construcción de carreteras mexicanas y esbozar sus impactos en la industria turística. También interesa realizar comparaciones con procesos ocurridos en Estados Unidos, pues pese a notables diferencias nacionales su construcción sería temporalmente próxima.

Las entreguerras demarcan este ensayo. La primera posguerra atestiguaría el comienzo de colaboraciones e intercambios de experiencias entre los diversos agentes que promovían actividades de "tourismo"; en esas actividades se encuentra el fermento que, al paso de varias décadas, terminaría situando a la industria sin chimeneas como fuente principalísima de los ingresos mexicanos (Payró, 1999). ${ }^{1}$ Para mostrar su temprana evolución, destacamos la relevancia de la carretera panamericana, puntualizando que no tendremos oportunidad de tratar sus aspectos técnicos ni sus diversos impactos territoriales que, por mucho, exceden estas resumidas líneas. El primer apartado esboza la concepción temprana de las redes carreteras y la formación de la industria automotriz comparando algunas experiencias en Estados Unidos y México. El segundo describe problemas derivados por paralelismos de trazos carreteros y vías férreas. El tercero describe pautas de consolidación del automóvil e impactos en la temprana industria del turismo. El cuarto revisa condiciones de infraestructura en proyectos de potencialidad turística, y el quinto muestra oportunidades económicas ligadas a la carretera panamericana.

\section{UNA NOTA COMPARATIVA EN LA TRANSPORTACIÓN}

En el siglo XIX, Estados Unidos comunicó sus ciudades mediante ferrocarriles. México los "adoptó" con retrasos y contradicciones (Coatsworth, 1984). ${ }^{2}$ Un ejercicio de contrastes observaría mayores atrasos en infraestructura portuaria y medios de navegación. Claro, por condiciones geográficas, la trans-

${ }^{1}$ En 1998 aportó fiscalmente 30000 millones de pesos, 15\% de la contribución total.

${ }^{2}$ Coatsworth estudió impactos sociales, costos económicos y alternativas existentes al adoptar esa industria para "desarrollar" al país. El resultado fue paradójico. 
portación pluvial (lagos y ríos) jamás podría acercarse a las condiciones que facilitaban la comunicación estadunidense.

En un marco amplio de sistemas de transportación sorprende lo poco que ha sido comparada la evolución de las modernas redes carreteras mexicanas y estadunidenses. Máxime porque pese a diferencias de escala o de capacidad profesional y técnica con la que se encaraban la construcción de infraestructura, los problemas enfrentados por funcionarios y empresarios de ambos países eran simultáneos y condujeron a comportamientos colaborativos. Compartirían una atmósfera de cambio de enfoques y principios, alineada por el deseo de salir de la depresión bajo la bandera del panamericanismo. ${ }^{3}$ Desde luego, tras esta bandera subyacían en distintos grados los viejos objetivos hegemonistas estadunidenses. En cualquier caso y previniendo esa posibilidad, la diplomacia mexicana estaba dispuesta a defender su programa reconstructivo nacionalista "tomando" la palabra a Washington y procurando cultivar acercamientos provechosos. Al respecto debiera anotarse que la clase dirigente mexicana sentía que esto era propicio toda vez que, desde el verano de 1933, Roosevelt decidió empujar una política de elevación del valor de la plata que favorecería la recuperación mexicana. ${ }^{4}$ En esta circunstancia el proyecto carretero panamericano fue recibido como un gesto modernizador $y$ de "buena vecindad". Más suspicaz el pueblo mexicano bautizó a la panamericana como la carretera "pocha" (Beals, 1937, p. 492), ${ }^{5}$ etiquetándola así como símbolo de una modernización espuria.

En los tempranos años veinte, parecía improbable organizar un sistema carretero coordinando esfuerzos binacionales. En Estados Unidos las empresas ferroviarias continuaban librando sus guerras, mientras su federalismo competitivo, diferencias subnacionales y políticas regulatorias ralentizaban su integración (Friedlaender, 1969). En México, los revolucionarios

${ }^{3}$ La más vieja "confección” de la bandera se atribuye a Simón Bolívar, pero bajo la promoción de Washington ya en la primera conferencia de la "Unión Panamericana" (1890), era clara la intención de constituir al hemisferio como una zona de libre comercio. Este trabajo se sitúa en la era Roosevelt con la implantación de su política de "buena vecindad".

${ }^{4}$ Sobre la reunión de Roosevelt con la delegación mexicana que conoció su decisión y la relevancia de integrar la participación de Canadá, Perú, Bolivia y Chile, véase Archivo Plutarco Elías Calles (en adelante APEC), gav. 63, exp. 109, leg. 5/7. Fideicomiso Archivo Plutarco Elías Calles y Fernando Torreblanca (en adelante FAPECYFT), México.

${ }^{5}$ El autor afirmó: "Panamericanismo es un término comercial, facturado en Estados Unidos y significa: 'compren nuestros productos'. Era un eslogan servido en banquetes “que apadrinaban compañías de cables, intereses navieros y fabricantes de automóviles”. 
disputaban el Estado dificultando proyectos integrales de gran calado. La revolución alteró fundamentalmente el funcionamiento ferroviario pues cada facción los consideraba cosa suya. Su manejo político degradó los caracteres técnicos que requería su administración. Trastocó su operación cotidiana, deformó jerarquías e incentivos al capacitar, seleccionar o disciplinar su heterogéneo personal y canceló el uso eficiente del equipo. Aspectos esenciales pasaron a ser temas secundarios. Además, representaban la mayor parte de la deuda externa justo cuando la revolución desplazaba sus influencias sobre las políticas públicas. Empero su proceso de deterioro fue entrecortado pues hubo varios intentos de reorganización. ${ }^{6}$

En 1936, la gestión obrera evidenciaría su ocaso (Azuela, 1985; Kuntz y Riguzzi, 1996; Vera, 1943). Este se aceleró con la política de construcción carretera para adaptar/adoptar la prometedora versatilidad automotriz, cuya competencia aceleraría el decaimiento ferrocarrilero. Decimos "aceleraría" porque la revolución los había dañado física y administrativamente. Es imposible cuantificar en este breve espacio los numerosos destrozos en vías, puentes, estaciones, equipo rodante, etc., que los diversos ejércitos causaron en ellos. A los daños administrativos que le infringió, hay que comenzar por su peculiar y previa integración bajo el rótulo Ferrocarriles Nacionales de México (FFNNM) (Grunstein, 2012); su denominada mexicanización que ocultaba una importante sobrecapitalización. Luego vendrían el caos monetario y seguida en varias etapas - que marcharon a la par de la guerra-su incautación. Hacia 1916-1917 estaban incautadas las líneas más importantes y para 1919 la empresa también fungía como "agencia de promoción electoral" (Vera, 1943, p. 71). El énfasis de este sesgo manifestaba claramente la preeminencia que tenían las decisiones políticas sobre las técnicas; el crecimiento del personal y el desalineamiento de sus funciones y la desorganización resultante sólo eran sus consecuencias lógicas. Desde el presidente Carranza hasta Calles se hicieron esfuerzos por reorganizarlos.

A diferencia de Estados Unidos, el porfiriato usó los primeros autos suntuariamente. Parece innecesario comentar que me refiero a los automóviles, pero debo subrayarlo, pues ante todo quiero establecer una diferencia relevante. Una diferencia que se aclara mejor con el ejemplo del célebre modelo $\mathrm{T}$ (Lizzie), de Ford, cuya enorme aceptación popular no sólo estaba fundada

${ }^{6}$ Elías Calles y Ávila Camacho alentaron avances que la contracción económica o la guerra frenaron. Grunstein (2008) y Valencia (2015) han reflexionado sobre esos proyectos. 
en su servicio de transportación, sino (y esto quiero enfatizarlo porque se desapercibe) en sus múltiples usos motrices; estos estaban facilitados por lo fácil que resulta desmontar su motor y aplicarlo a un amplio rango de tareas campiranas, la curiosidad y el instrumental de los farmers complementó el proceso. La asociación de estas dos características les dio su enorme arraigo popular y con esto quiero decir -sobre todo- agrario, tal y como lo ha destacado muy agudamente Wik (1972). ${ }^{7}$ En México la revolución también diversificaba usos sobre bases sociales muy distintas: comenzó por los bélicos. Desde luego, la mayoría del pueblo continuaba transportándose a pie, caballo o ferrocarril. Pudiera decirse que la revolución matizó su adopción incluso extravagantemente: modernizó el bandidaje (Sánchez, 1997), ${ }^{8}$ la seguridad (policía y bomberos) y acentuó su carácter de símbolo de status. Como arquetipos, los autos preservarían su sentido experimental y novedoso durante la década de los veinte. Así lo confirman abundantes fotografías, escenas literarias o peatones trágicamente atropellados "en cámara lenta". La expedición punitiva de Pershing también lo ejemplifica, siendo la primera gran movilización militar motorizada terrestre antes de que Estados Unidos decidiera combatir en la primera guerra mundial, 1914-1918 (Kersaw, 2002; Ripley, 2003). ${ }^{9}$

Inicialmente el Estado mexicano intentó absorber el empuje del mercado estadunidense en favor del crecimiento endógeno, asimilando su experiencia industrial por la vía de establecer plantas de ensamble y autopartes. Infortunadamente, en el largo plazo, dichos esfuerzos no germinaron para desarrollar una marca propia, como sucedería con los regímenes autoritarios de Japón, Alemania, Rusia, Italia e incluso, para un plazo menor, Argentina. ${ }^{10}$

${ }^{7}$ No es fácil identificar los usos de los primeros camiones durante el porfiriato, pues no había incentivos que alentaran su importación por empresarios que los conocían e incluso los requerían. Los desincentivaba la falta de infraestructura, servicios, combustibles y refacciones. Algunas compañías (e.g., Cervecera de Toluca) los empleaban para sus entregas. El Estado porfiriano no se apresuró a proveer a bomberos o al correo cuando otros Estados ya lo hacían. Su empleo en la minería mexicana también conoció otros obstáculos -asociados al modo como interactuaban las pequeñas empresas con las predominantes- $y$ a la inestabilidad de los precios metalíferos, antes de 1905 y luego de 1907. Es claro que su situación no semejaba la de Estados Unidos.

${ }^{8}$ La famosa banda del automóvil gris, popularmente identificada con políticos y policías. Sus víctimas no reconocerían el automóvil ¿Fiat, Lancia, Chalmers, Packard? Sánchez asumiría que fueron varias bandas; aparentemente aficionadas al gris.

9 Subsistía el empleo de energía animal por resistencias al cambio en ejércitos, altos costos del rearme, el carácter experimental de las tecnologías, etcétera.

${ }^{10}$ Fundada en 1927, en Córdoba, la Fábrica Argentina de Aviones (FADA), hacia el final de los años cuarenta albergó varios laboratorios para desarrollar vehículos terrestres y marítimos 
Advirtamos que la cuestión de ¿por qué no se asimilaron estas experiencias?, no ha recibido una respuesta sistemática.

Una diferencia crucial entre la industria automotriz estadunidense y las europeas fue la rápida masividad de la primera. La diferencia no radicó en el mero asunto tecnológico, sino en cambios de gestión laboral, estandarización de partes automotrices, caída de precios y demanda. El asunto técnico, la preocupación de los inventores del xIx: el motor de combustión interna fue de interés restringido, incluso después que G. Selden, en 1879, obtuviera la patente del motor (Perkin, 1976, pp. 38-40). Esto se confirma porque otros inventores aún apostaban por el vapor, logrando velocidades impensables para motores que funcionaban con derivados del petróleo. Realmente, su éxito llegó cuando articuló la masividad de producción y demanda y esto sólo ocurrió con el maridaje del famoso Lizzie y los granjeros estadunidenses.

El "Modelo T" fue célebre porque su versatilidad incrementó la productividad y radios de acción de los granjeros. Debido a sus conocimientos mecánicos previos pudieron adaptarlo a múltiples tareas (no sólo traslados) e incluso sugerirían numerosos cambios a Henry Ford (Wik, 1972). Él observaba atento las necesidades de sus principales clientes $y$, simultáneamente, también alentaba el consumo urbano. Claro, la producción masiva reducía costos que retroalimentaban su aceptación; la mayoría de los autos producidos en Estados Unidos tenían precios inferiores a 1000 dólares (Department of Commerce, 1926, pp. 269 y 393). La estandarización de autopartes, la reorganización de procesos de trabajo, el acceso a créditos bancarios y un ambiente institucional de prosperidad facilitaron el fenómeno. Las familias estadunidenses con automóvil se multiplicaron (Moulton, 1933; Rose, 1979). En 1895 el anuario de comercio contó 300 automóviles producidos (integrando camiones); 30 años después eran 4314746 unidades. En 1925, Estados Unidos contaba con un parque vehicular de 20000 000: un vehículo por cada seis personas. Este espectacular crecimiento fue constatado por el Departamento de Comercio estadunidense (Department of Commerce, 1926, pp. 269 y 393). El contraste con México era notable. México tenía entonces 37824 vehículos:

comercializables. Un corolario de ese proceso fue transformarla en Industrias Aeronáuticas y Mecánicas del Estado (IAME) que produjo - casi artesanalmente- durante cuatro años el Justicialista; sólo su motor (Porsche-Boxter, $1500 \mathrm{cc}$ ) era importado. Su experiencia y el aliento peronista influirían en la instalación de Industrias Kaiser Argentina (IKA) que fabricó el Kaiser, la Kaiser Estanciera y del célebre "petitero", entre otros autos fácilmente identificables (McCloud, 2015). Estas experiencias tenían rasgos semejantes con Aeroplanos Suecos Sociedad Anónima, SAAB. 
uno por cada 376 habitantes. En Cuba, con número similar de autos, el índice era menor: uno por cada 83 habitantes. México y Cuba eran importantes importadores de autos estadunidenses. Falta observar que la depresión impondría un retroceso al crecimiento de la planta automotriz que se repetiría en 1938 y con la segunda guerra.

La expansión de entreguerras hizo a la industria automotriz la industria líder de la economía estadunidense y a Henry Ford lo volvió su gran capitán. Su éxito primario se aclara por haber adaptado multifuncionalmente su "modelo T" y haber facilitado la comercialización agrícola al extender el radio de actividades de los farmers. Poco después el Lizzie también transformó las ciudades estadunidenses. Chicago, Nueva York, Los Ángeles, Pittsburgh, etc., cambiarían normas y estructuras para adaptarse al nuevo axis cultural. El fenómeno también se extendía internacionalmente con otros ritmos y ejes espaciales. La vertiginosa expansión automotriz de la década de los veinte aclaró que las fases experimentales quedaban atrás y que el automóvil sería el nuevo transporte entre las ciudades y en estas. Aunque también se percibía que las ciudades reaccionaban más rápido al desafío adaptativo que la construcción de las carreteras que las comunicaban.

El contraste urbano de ambos países era prístino, pero en sus incipientes carreteras, las diferencias eran menores. Dado este carácter existían puntos comunes, como el que no estuvieran decantadas todas las ideas en su derredor. El enfrentamiento con las compañías ferrocarrileras era intenso; los presidentes Roosevelt y Cárdenas usarían primariamente la construcción de carreteras para atenuar el desempleo. Aunque los discursos oficiales hacían gala de visiones comprehensivas (Holt, 1923), lo que predominó al construirlas fueron los "criterios" pragmáticos contra la depresión. Esta visión reactiva redundaría en disfuncionalidades cuando ya era necesario crear redes carreteras articuladas.

\section{PARALELISMO Y CENTRALIZACIÓN EN MÉXICO}

Una diferencia en los proyectos carreteros fue el grado y la coherencia de la intervención estatal en México y Estados Unidos. Desafortunadamente México siguió políticas contradictorias que aceleraron el decaimiento del ferrocarril y acentuaron el centralismo comunicacional y económico. Una clave distorsionante fue construir carreteras entre la ciudad de México y ciudades 
importantes próximas como Puebla, Pachuca, Cuernavaca, Cuautla, Toluca y Querétaro que alimentaban sus tráficos humanos y comerciales. Esas carreteras provocarían que el autotransporte sustrajera al ferrocarril cargas y flujos poblacionales constantemente. Esto afectó a su principal centro ferroviario, la ciudad de México y en general a la red ferroviaria pues provocó que el equilibrio de costos - por carga ferroviaria, calculada por el indicador tonelada/ kilómetro- se desplazara a recorridos más largos; entre 1924 y 1944 el indicador subió poco más de 50\% el desplazamiento (Kuntz y Riguzzi, 1996, p. 296).

En contraste, las compañías ferrocarrileras estadunidenses desconocían la competencia automotriz asociada con los fenómenos de centralización y paralelismo que "desarrollaba" México. Por su fuerza, aquellas sorteaban intentos regulatorios de la Comisión Interestatal de Comercio (ICC) (Friedlaender, 1969, p. 17). Además, las decisiones para construir carreteras (terracería o revestimiento) eran dispersas y solían definirse por el nivel de agencia (condados, estados y gobierno federal) de los trabajos, donde predominaban las "municipales" (counties). Aunque en la década de los treinta comenzó a demandarse una carretera interestatal "transcontinental", esta sólo fue construida hasta la "Federal-Aid Highway Act", de 1952. Uno de sus promotores fue Dwight Eisenhower, quien conocía la heterogeneidad dominante desde 1919, cuando viajó de océano a océano estudiando caminos interestatales (Weingroff, 1996). Otros fueron los tempranos touring clubs, sus promocionales y convenciones lo testimonian (Lewis, 1997). También sociedades de ingenieros, grupos de interés locales, gobiernos de ciudades grandes, etc., que impulsaban suburbios o corredores industriales. Una asociación que integró estos intereses, digámoslo así, tanto de los "expertos profanos" como de profesionales y empresarios de la construcción, fue la American Road Builders Association (ARBA).

En México, surgió una visión federal con la Comisión Nacional de Caminos (CNC) bajo la presidencia de Álvaro Obregón, pero tenía pocos recursos, titubeaba ante los ferrocarriles y su organización era incipiente. Con una correa política más fuerte la CNC imponía (o negociaba sobre bases más firmes) decisiones a los empobrecidos municipios y estados subnacionales que optaban por colaborar incluso con recursos o trabajo literalmente gratuitos. No extraña que pronto la CNC se planteara construir una carretera interoceánica con eje en la capital mexicana. El presidente Plutarco Elías Calles avanzó el plan con la Acapulco-México (1927) que uniría con la México-Puebla (1925) para finalizar en Veracruz. Otra área de la construcción carretera que conocería modificaciones importantes sería la de su financiamiento; iniciaron soportadas 
-sobre todo- por impuestos especiales: la base fue el aumento a gravámenes de tabacos y gasolinas (tres a seis centavos entre 1925 y 1931). Así, se seguía el ejemplo estadunidense, buscando que el beneficiario devolviera una fracción al contribuyente, sin embargo, como aún era pequeño el consumo de gasolina, la fuente resultó insuficiente. Ante esto decidió destinarse una partida presupuestal que promedió anualmente 11500000 pesos entre 1925 y 1934. Con el presidente Cárdenas, la partida crecería a 270000000 de pesos, considerada como monto global de su sexenio. La presidencia de Ávila Camacho (19401946) expandió el heredado problema financiero de los bonos de caminos que infortunadamente la presidencia alemanista (1946-1952) tampoco pudo resolver; con mucho optimismo se ha propuesto lo contrario (Bess, 2017). ${ }^{11}$

Desafortunadamente la gestión callista fue contradictoria en sus proyectos de comunicación terrestre, y mientras por un lado pregonó su deseo de reorganizar los ferrocarriles, por otro preservó, acentuada, la práctica de construir carreteras paralelas a ferrocarriles. Hay muchos ejemplos. En el camino que se proyectaba para Veracruz ya operaban dos ferrocarriles: el Mexicano y el Interoceánico. Así, la nueva carretera sería paralela a una u otra empresa. El que saldría de la ciudad de México a Acapulco sería paralelo al ferrocarril México-Balsas, en varios tramos. En la Panamericana 600 kilómetros corrían a la par. Había paralelismos completos de Chihuahua a Ciudad Juárez; de Monclova a Piedras Negras; de Torreón a Saltillo; de Saltillo a Monterrey y de la capital neoleonesa a Matamoros. El paralelismo amenazaba a cualquier nueva inversión ferroviaria porque reducía su rentabilidad por la simple vía de incrementar la competencia de los automotores. Esto afectaba especialmente en distancias cortas y en cargas que demandaban mayor flexibilidad por peso o volumen. Ya señalamos que esta situación resultó ser muy sensible entre la capital mexicana y las capitales provinciales que la rodean: Toluca, Cuernavaca, Puebla, Querétaro y Pachuca. Por su versatilidad en carga, hora-

${ }^{11}$ Como cualquier otra emisión de bonos, estos integraban la deuda pública y se saldaba con transferencias fiscales futuras y otros instrumentos. No podemos tratar con amplitud los problemas de este método de financiamiento que, indudablemente, acentuó el proceso inflacionario en México durante 1942-1945. Aquí anotaremos que el avilacamachismo erogó 579000000 de pesos, de los que $77.24 \%$ se costearon con bonos y lo restante con impuestos, véase Sousa (1946, pp. 417 y ss.). Este método se modificó al final del alemanismo al introducir el sistema de peaje en la autopista México-Cuernavaca, que -por cierto- suscitó una gran controversia pública. Los bonos de caminos eran una parte sustantiva del famoso sobregiro del gobierno federal con Banco de México, posteriormente quedaron integrados a la cuenta "valores diversos" de sus informes anuales. 
rios y precios, los automotores adelgazaban la renta ferroviaria y aceleraban la centralización urbana, económica y política. Terminarían por formar una megalópolis intransitable.

\section{LA CONSOLIDACIÓN AUTOMOTRIZ}

El segundo lustro de la década de los años veinte combinaba más autos con nuevas carreteras y más "excursionistas" deseosos de transitarlas. Como sucedía en Estados Unidos, su incipiente articulación de caminos vecinales e interestatales dinamizaba el transporte humano y comercial. Siendo relativamente pequeña, la escala de inversión automotriz -de uso comercial-ensanchaba los rangos de los tipos de propiedad y de operación, lo que también parecía inducir márgenes de rentabilidad relativamente amplios a los transportistas; es probable que ello haya incentivado el crecimiento de cooperativas de transportistas, pero también su transformación en empresas regionalmente predominantes, aunque estas sólo aparecían como tendencias en estas etapas de arranque (1920 a 1940) y aún demandan investigaciones más específicas. ${ }^{12}$

Como vimos, el gran éxito automotriz estadunidense obedecía a muchas razones, siendo quizás la más poderosa su accesibilidad dado el descenso de los precios de los automóviles; un descenso, en buena medida, fundado en su eficiente producción y la continua estandarización de piezas. Esta estandarización suele pasar desapercibida, pero fue muy dramática y queda ejemplificada en cualquier autoparte: en los sistemas de freno, en el diámetro de los pistones, en el tránsito de las llantas duras a los neumáticos o en sus dimensiones (había al menos 40 medidas), tema clave para capacidades de carga y disminución del desgaste carretero (Department of Commerce, 1928, pp. 440445). Este descenso sería consistente hasta que lo interrumpió la depresión.

Los "fantásticos veintes" expandieron la industria vigorosamente en todos los continentes. Aunque Estados Unidos adquirió rápidamente ventaja en particular con respecto a sus más próximos competidores europeos. Al principio de la década de 1920, la discrepancia no era tan notoria pero los

12 Afortunadamente hay algunas para las décadas siguientes (Álvarez, 2017). En la ciudad de México, la expansión de transporte público en "camiones" aparece ligada a la huelga de tranviarios de 1926, siendo ampliamente reportada por la prensa. Entrecomillo camiones porque, la mayoría parecen haber sido trucks (camionetas adaptadas vernáculamente) y autos grandes los que respondieron a esa súbita demanda. 
tiempos la aclararían sobre una base evidente: el tiempo de fabricación de los vehículos. No es fácil establecer una comparación precisa, sin embargo, si se establece un rango promedio de 90 horas entre las empresas europeas más reconocidas, no parece que caigamos en un abuso estimativo. En contraste, Ford gastaba menos de 20 horas en producir su popular Lizzie. La consolidación fue vertiginosa y trascendente para México que importaba más vehículos estadunidenses que Suecia, Bélgica, Inglaterra o Cuba. El proceso de consolidación de sus exportaciones conoció altibajos de 1913 a1926, pero luego de 1927 pareció consolidarse por encima de $11.3 \%$ del total de vehículos que producía (cerca de 3400 000); en 1928 exportó 11.6\% sobre una base de 4357000 (Department of Commerce, 1929, p. 454). ${ }^{13}$ Pronto aparecieron comercializadores de autos usados y nuevos, como los hermanos Azcárraga. ${ }^{14}$ Como solía suceder con muchos otros aparatos mecánicos, los autos usados eran adquiridos sobre todo en las fronteras norteñas y sus propietarios solían ejercer presión política para beneficiarse de exenciones fiscales arguyendo, por lo general, que los empleaban como instrumentos de trabajo. Atento a estos procesos el gobierno realizó modificaciones fiscales para alentar la instalación de plantas armadoras, ${ }^{15}$ el denominado "Completely Knocked Down", armado final de conjuntos que ha sido subestimado o descontextualizado por estudios sociológicos (González, 1992; Samstad, 1996). La combinación de restricciones e incentivos a empresarios propició que comercializadores-importadores destinaran capitales a esas plantas o buscaran alianzas con compañías estadunidenses; tal sucedió a finales de la década de los treinta con Automotriz O’Farril, S. A., General Motors Co. de México, S. A., Automex, tycsA, IMBA-Mex, Carrocerías González e Industrias Metálicas de Monterrey. En la década de los cuarenta aumentarían con Automotriz de México, S. A., International Harvester de México, S. A., Willys Mexicana, S. A., y

${ }^{13}$ Infortunadamente no podemos desglosar de esa fuente el porcentaje de camionetas y camiones exportados. Sin embargo, de los reportes de años previos y de este se colige que era una fracción muy menor. Como es sabido esta tendencia se interrumpió después de 1929.

${ }^{14}$ Emilio, Gastón y Rogerio Azcárraga Vidaurreta con vínculos empresariales en Monterrey, Texas y Nueva Orleáns se asociaron con Stanley Copeland para importar autos Ford. La "Azcarraga Copeland" tuvo varias agencias antes de transformarse en la "Compañía Automotriz Nacional, S. A."

${ }^{15}$ La Ley de Fomento a las Industrias Nuevas y Necesarias (abril 1926) y otras similares de 1931 facilitaban crear plantas de montaje. La sustitución de partes importadas fue un proceso más lento y errático. 
Automóviles Ingleses. Y para los años cincuenta, con Diesel Nacional, Studebaker-Packard, Representaciones Delta y Reo de México.

Pese a interrupciones en el crecimiento de la planta automotriz (la depresión y la expropiación petrolera; que encarecerían vehículos, repuestos, abasto de gasolina, etc.), un rasgo muy llamativo de la tendencia fue el bajo costo al que sucedía (véase cuadro 1). La fundación de "armadoras" y esas interrupciones alimentarían la idea de formar una industria automotriz nacional.

No incluimos el número de automóviles que podrían ser empleados en el servicio de transportación (taxis), pues la imprecisión sería muy alta. ${ }^{16}$ Con todo queremos llamar la atención sobre un contraste. Además, los gastos correspondientes a camiones de pasajeros y de carga excluían las inversiones carreteras, es decir, no incluían el gasto gubernamental (federal y estatal) que aclaraba su éxito. En otro contraste, las inversiones ferrocarrileras eran fundamentalmente gubernamentales. Sus problemas eran viejos pese a cambios revolucionarios, con Obregón el demérito relevante fue administrativo: "se acababa la era de los errores y se iniciaba la de la improvisación y el favoritismo" (Vera, 1943, p. 85). Cárdenas trasladaría su gestión a una administración obrera que encareció costos, incrementó accidentes y perdió clientes (Beltrán, 2015). También los tranvías -cuyo nicho principal era la ciudad de Méxicodisminuían su rentabilidad, sufrían robos de luz, abundancia de free riders y radicalismo sindical (Armstrong y Nelles, 1984). Un contraejemplo fueron los tranvías de Veracruz, vendidos a una cooperativa de exobreros quienes la administraron bien y dieron servicio regular permitiendo mejorar salarios y mantener el equipo. Su factor más auspicioso fue no enfrentar una gran competencia camionera (Cooperativas, 1935).

Mientras el ferrocarril o los tranvías padecían defectos notables, los que adolecían los automotores eran incipientes. La atmósfera de luchas populares también favoreció sindicalizaciones de choferes en Yucatán, ciudad de México y Puebla, con resultados diversos. En general no lastimaron la consolidación de incipientes compañías de autotransporte; una excepción sucedió al iniciar 1935, cuando una "huelga" bloqueó el servicio entre México y Puebla. Interesantemente, la protesta subrayó el excesivo número de autos

${ }_{16}$ Tendría, desde luego, que ser una fracción del parque vehicular base, que por entonces (1932-1934) debía oscilar por el orden de las 65000 unidades. Sin embargo, estas cifras son controversiales y muy probablemente carecen de subregistros. Otras dificultades radican en estimar correctamente el efecto de la contracción de las importaciones (formalizadas e internamientos ilegales) con motivo de la depresión. 
Cuadro 1. Valor de inversiones en transportes, México, 1934-1940

$\begin{array}{lrr}\text { Tipo de transporte } & \text { Monto de la inversión (pesos) } & \text { Porcentaje } \\ \text { Ferrocarriles } & 451198421 & 83.0 \\ \text { Tranvías } & 41095900 & 7.6 \\ \text { Camiones de pasajeros } & 27984921 & 5.1 \\ \text { Camiones de carga } & 6485531 & 1.2 \\ \text { Navegación } & 7359591 & 1.4 \\ \text { Transportes aéreos } & 7139378 & 1.3 \\ \text { "varios" } & 2171550 & 0.4 \\ \text { Total } & 543435292 & 100\end{array}$

Fuente: Secretaría de Economía Nacional, Dirección General de Estadística (1940).

de alquiler, pero también otras causas alentaban el conflicto, como el control de las rutas. Parece lógico que dados los bajos montos de inversión surgieran problemas de inestabilidad y rentabilidad en circuitos muy transitados, pero requerimos más estudios de esas organizaciones transportistas que incluían pequeñas cooperativas y acaudalados empresarios. Otro factor por considerar eran las innovaciones del mercado camionero, tanto porque había más competencia entre muchas compañías pequeñas como porque existía mayor variedad de camiones que podían soportar tareas más pesadas, como White, International, Reo, GMC, Ford, Dodge, Federal, Diamond, Chevrolet, Willys, Hupmobile, Nash, Hudson, etc. No obstante, en el transporte de personas continuaban dando gran "pelea" las camionetas y autos "coupé" de todo propósito; claro, excluyendo -por lo regular-autos de mayor precio, como, por ejemplo, Buick, Graham, Lincoln, Cadillac o Packard. No podemos ofrecer un índice de precios del mercado automotriz de la década de los treinta, pero observaremos dos puntos: a) los precios eran superiores a los de la década anterior (cuando los precios para camiones de pasajeros y carga oscilaron entre 1000 y 1500 dólares (cfr. Department of Commerce, 1929), y, b) un camión o automóvil recién importado pagaba derechos de importación, tarifas por flete y fluctuaciones cambiarias que lastimarían la renovación vehicular, como 
sucedería en $1938 .{ }^{17}$ Otro índice de la continuidad de la demanda de autos importados y la importancia de los crecientes flujos de automóviles se refleja en el cuadro 2.

Valga una breve anotación respecto de los valores de los autos importados en los años de inicio (1921) y fin (1939). En 1921 México pagó 5200000 dólares por los 6750 autos importados; mientras que en 1939 pagó 8700000 dólares por 8772 . Números que indican que el promedio del valor unitario parecía estar subiendo muy probablemente por el consumo de vehículos de mejores gamas. ${ }^{18}$ El mayor uso del automóvil se reflejaba no sólo en los vehículos importados sino también en los internados por turistas extranjeros. Entre los primeros estudios relativos sobre flujos vehiculares con propósito turístico está el de Orozco Escobosa, miembro del Comité Nacional de Turismo. Con las reservas correspondientes a las dificultades de verificación lo reproducimos para presentar una idea de las aportaciones fiscales del turismo; esto también ilustra la importancia que comenzaban a asignarle funcionarios gubernamentales y promotores privados (véase cuadro 3).

Orozco comparó sus datos contra el flujo turístico estadunidense a Canadá, donde las cifras eran abrumadoramente mayores; estableciendo para ese caso poco más de 13200000 turistas movidos por automóviles, tren y barco, con derramas que rondaban los 250000000 de dólares. ${ }^{19}$ Una cifra a todas luces muy atractiva para México.

Desde luego que para incrementar los ingresos había que atraer al turismo y para esto había que realizar muchas inversiones en infraestructura de transporte, hoteles y facilidad de operación para agencias de viajes, es decir, desarrollar una industria desconocida. Se especulaba si un engranaje clave serían las agencias promotoras. Con vacilaciones surgirían algunas, el cálculo

${ }^{17}$ CMLXxv, doc. 30354, dic. 1938. Archivo Luis Montes de Oca. Centro de Estudios Históricos de México CARso (en adelante CeHM-CARSo).

${ }^{18}$ Es importante que se haya sostenido un ritmo de importación, sobre todo porque a partir de 1926 ya operaban una planta de ensamblado Ford, que fue "ampliada" en 1932 (Anaya, 2013). La interacción de la nueva oferta interna y las importaciones fue compleja y coincidente con otros procesos que afectaban el mercado local e internacional. También la estadística de camionetas y autobuses requiere mayor análisis, entre otras razones porque fue más dinámica que la década previa, por haber más marcas competidoras, por la mayor diversificación de usos e, incluso, por la respuesta de la ensambladora Ford.

${ }^{19}$ Según cifras del Dominion Bureau of Statistics, cfr., CMLXXv, doc. 30989. CEHM-CARso, México. Lo más atractivo era que el promedio de gasto de los turistas estadunidenses en Canadá era menor a lo gastado por los que visitaban México. 
Cuadro 2. Importaciones de autos desde Estado Unidos y Canadá, 1921-1929 y 1937-1939 (unidades)

$\begin{array}{llllllllllll}1921 & 1922 & 1923 & 1924 & 1925 & 1926 & 1927 & 1928 & 1929 & 1937 & 1938 & 1939\end{array}$

Automóviles incluyendo chasis

\begin{tabular}{|c|c|c|c|c|c|c|c|c|c|c|c|c|}
\hline (número) & 6750 & 7279 & 7559 & 8689 & 12560 & 9809 & 6028 & 12841 & 12676 & 13302 & 4153 & 8772 \\
\hline rtes & & & & & & & & & & & & \\
\hline (toneladas) & & & & 244 & 428 & & & & & 1023 & 839 & 1058 \\
\hline mionetas y autobuses & & & & & & & & & & 12339 & 5909 & 243 \\
\hline tores de camionetas y cal & & 983 & 1011 & 1393 & 3586 & 2203 & 1743 & 3274 & 3796 & & & \\
\hline
\end{tabular}

Fuente: elaboración propia basada en Department of Commerce (1926, 1928); Secretaría de Economía Nacional, Dirección General de Estadística (1940). Los datos recopilados no convergen con los libros de la misma fuente que detallan el comercio con países extranjeros. Hay inconsistencias entre unos y otros. Habiendo detectado más errores, tanto simples como de clasificación en los segundos nos pareció prudente recoger las primeras cifras, sobre todo suponiendo -lo que parece plausible- que los segundos no fueran sino resúmenes de los primeros. Cabe igualmente observar que los anuarios no aclaran la diferencia entre passenger cars y automóviles (antes de 1930 aparecen como sinónimos mientras que después parecen referir objetos distintos), circunstancia similar suele aparecer con camionetas y autobuses. 
Cuadro 3. Cálculo de gastos de turistas extranjeros en México (1937) (Carretera de Laredo y Ferrocarriles Nacionales de México)

$\begin{array}{ccccc}\begin{array}{c}\text { Mediode } \\ \text { transporte }\end{array} & \begin{array}{c}\text { Número } \\ \text { deturistas }\end{array} & \begin{array}{c}\text { Gasto en dólares } \\ \text { promedio por turistas }\end{array} & \begin{array}{c}\text { Total } \\ \text { dólares }\end{array} & \text { Total pesos } \\ \text { Auto } & 120000 & 36 & 4320000 & 15552000 \\ \text { FFCC N de M } & 19500 & 200 & 3900000 & 14040000 \\ & & & 8220000 & 29592000\end{array}$

Fuente: CMLXXV, doc. 30989, febrero 23, 1938, J. M. Orozco Escobosa, Memorándum para el Comité Nacional de Turismo. CEHM-CARso, México.

que hacían los primeros promotores era que sólo recibirían una fracción muy menor de lo que los turistas pagarían como alojamiento, que no podrían incidir en la elección de hoteles y transportes y menos aún "conducir" a los turistas que llegaban por automóvil. Su expectativa empeoraba estimando que apenas podrían manejar una fracción pequeña de los turistas internados por ferrocarril. Los promotores o agentes más relevantes -estimaban- tendrían que proceder del control de hoteles y transportes.

\section{INFRAESTRUCTURA Y OPORTUNIDADES}

El desarrollo de infraestructura carretera era crucial para incentivar la industria turística y la de sus operadores. Como advertimos, las primeras reacciones de las agencias de viaje fueron cautas; creían que pocos visitantes rentarían autos, colegían que ganarían poco por alojamiento y que no incidirían en la elección de hoteles.

Los flujos y rutas turísticos de 1937 eran distintos a los que hoy imaginamos: 50\% del turismo viajaba a la ciudad de México, el resto iba a Monterrey y otros puntos norteños. Su promedio de gastos por automóvil eran 36 dólares. Pero 1937 fue un año especial con sesgo positivo por la inauguración de la Panamericana. Promotores mexicanos y estadunidenses querían explotarla luego de que fracasaran intentos en Yucatán y porque la conexión con Acapulco todavía significaba una desviación importante para los visitantes que alcanzaban la ciudad de México. Yucatán fue ejemplo de contrastes: con- 
vergieron emprendedores locales y autoridades estatales y federales para impulsarlo, pero hubo inexperiencia, candor, repetición de vicios y dificultades de coordinación. El experimento falló porque Puerto Progreso estaba "desconectado" de los puertos del golfo, porque las navieras no se interesaron en sus pequeños flujos y también porque las sociedades interesadas en desarrollar polos turísticos -como la AMA-, orientadas a comunicaciones terrestres- no tenían recursos propios para generar opciones navales.

El experimento evidenció deficiencias infraestructurales marítimas y carreteras. Al noroeste del país, en Tijuana, surgían más beneficios con menores obstáculos, sin embargo, las autoridades estadunidenses prohibieron el tránsito en horarios que incomodaban al turismo. El ambiente de la prohibición había alentado la edificación de casinos que atraían al turismo estadunidense. La permisividad de gobernadores-empresarios (e.g., Esteban Cantú, Abelardo Rodríguez, José María Tapia, etc.) creó negocios florecientes ante los cuales no hubo una actitud homogénea del gobierno federal hasta 1935 cuando fueron clausurados (Cárdenas, 1979).

Luego de una década de trabajos y más de 60000000 de pesos, en la esquina noreste concluía la Panamericana. Proyecto ambicioso que unía Laredo con la capital. Se esperaba que demandara más infraestructura, además de atraer nuevas industrias y proyectos sociales. Además, contaría con su conexión a la red carretera norteamericana que prometía inaugurar una memorable era de caravanas turísticas. El siguiente reto sería unirla con Guatemala.

"La Panamericana reactivó el interés de promotores norteamericanos y cubanos para organizar circuitos de viaje en el Golfo de México", ${ }^{20}$ pero los viejos obstáculos persistirían. ${ }^{21}$ La Secretaría de Comunicaciones consideró que el pésimo servicio de la Compañía de Transportes Marítimos y Fluviales traería tantos inconvenientes, "que más que fomentar el turismo lo alejaría de Yucatán". ${ }^{22}$ Circunstancias políticas del cardenismo también desalentaban futuras inversiones: el reparto agrario agitó la península, siguió la expropiación petrolera (1938) y luego campañas negras y boicots. El gobierno

${ }^{20}$ CMLXXv, doc. 30366, 1937. CeHM-CARso, México.

${ }^{21}$ Freeman (2010) ha explorado las competencias o rivalidades comerciales de los promotores cubanos. Y, naturalmente, esta posición existía y era fuerte. Aquí llamamos la atención a un punto de vista que enfatizaba la complementariedad, mismo que no prosperó por las razones expuestas.

22 CMLXXv, docs. 28228 y 28279, 1937. CEHM-CARso, México. 
respondió reorientando prioridades y recursos ante la inestabilidad política y económica.

Advirtamos que los boicots estadunidenses fueron suavizados por el embajador Josephus Daniels. Jugando a favor de la comprensión binacional, presentaba imágenes positivas del presidente Cárdenas en Washington y en México, ayudó a cambiar la idea predominante del Panamericanismo. Nacionalista, la diplomacia mostraba cautela ante esfuerzos continentales por desarrollar nuevos proyectos de infraestructura, mientras Cárdenas (1979), intentaba reducir tensiones, presumir apertura y animar la solidaridad internacional. La Panamericana le dio publicidad positiva, incluso la denominó primer tramo sosteniendo el compromiso de conducirla a Sudamérica. Su eco internacional animó el Tercer Congreso Panamericano de Carreteras (Santiago de Chile, enero de 1938) y favoreció la candidatura mexicana para el siguiente congreso, ${ }^{23}$ pero las prioridades cambiaron por la segunda guerra mundial y concomitantes cambios de la agenda estadunidense.

Así, la Panamericana propició proyectos "reconstructivos" nacionales y mercados internacionales al impulsar agroindustrias en territorios que atravesaba: la azucarera en El Mante, la citrícola en San Roberto y Montemorelos o la algodonera en Matamoros. No obstante, años después, el nuevo trazo carretero Querétaro-San Luis Potosí le sustrajo flujos y desplazó el eje turístico internacional que formaba la Panamericana, es decir, marcó su declive. Además, volvió secundarios otros caminos "petrolizados" levantados sobre caminos coloniales, como el que mal comunicaba el sur de Tamaulipas con su centro-norte (Hernández, 2001) y que venía reorganizando corredores económicos regionales.

Al inaugurar la Panamericana, Cárdenas cosechó frutos de antiguos jefes y adversarios. Reconociendo su importancia y las expectativas que generaba, instruyó a su secretario de Comunicaciones, Francisco Mújica, a que preparara una ceremonia de apertura el 1 de julio, en Laredo, en la que reunió a altos funcionarios de ambos países y para la que solicitó confirmación rigurosa previniendo molestias por falta de alojamiento y alimentos. Laredo carecía de infraestructura y para subsanarla se formó una Junta de Mejoras Materiales que reformaría ampliamente este punto fronterizo. ${ }^{24}$ Esto era un objetivo asociado con otros que pretendía detonar la carretera Panamericana.

23 CMLXXV, doc. 32823, 1939. CEHM-CARso, México.

${ }^{24}$ CMLXXV, docs. 26692, 26996 y 27133, 1936. CEHM-CARso, México. 


\section{COOPERACIÓN Y NEGOCIOS BINACIONALES}

Laredo tuvo un impacto excepcional. La expectativa general era detonar nuevas industrias, servicios y beneficiar poblaciones. Sonaba plausible por la multiplicidad de necesidades, iniciando por las básicas de salud. El ingeniero José Rivera encabezó la potabilización del agua en varias ciudades, coincidiendo con trabajos similares en otras ciudades pequeñas, como Cuernavaca, San Miguel de Allende o Taxco, sobre las que también se pensaba explotar su potencial turístico. El temor a la mala calidad del agua era difícil de erradicar entre turistas pues arraigaba en imaginarios confusos, creían que bebiéndola contraerían paludismo. ${ }^{25}$ Así, además de infraestructura requerían campañas informativas.

Rivera ejemplificaba la trayectoria de los emprendedores tras las redes carreteras. Trabajó para Byrne Brothers Construction Company, de Chicago, contratada por la CNC; trabajó en esta Comisión y fue secretario de la AMA. El presidente de AMA, Luis Montes de Oca, otro buen representante, ocupó puestos de mayor responsabilidad, destacando el haber sido Contralor, secretario de Hacienda y director del Banco de México. En conjunto son destacables los impulsos de esas organizaciones para construir carreteras, hoteles, restaurantes, para apoyar esfuerzos conservacionistas, de asistencia vial, y edición de mapas que facilitaban la actividad turística. Desafortunadamente, carecemos de espacio para abundar sobre su aportación a la logística que permitiría el funcionamiento de las nuevas redes carreteras.

Otros efectos importantes fueron los ramales. Su construcción lucía menos lógica que el tronco principal. En la Panamericana destacaron tres: 1) el enlace con el Puerto de Tampico; 2) el de Ixmiquilpan con Querétaro y, 3) el de Matamoros a Ciudad Victoria. El primero se gestó al final de 1936, el segundo se abrió al iniciar 1940 y el tercero apareció como proyecto a mediados de 1940. Todos fueron promovidos por intereses locales y en su mayoría tuvieron un impacto importante en la reorganización territorial. Lo que constata el sinfín de expectativas que generó la Panamericana o Carretera Nacional Núm. 85.

Todos los ramales serían impulsados por comerciantes locales que interactuarían con autoridades como el jefe del Departamento de Turismo, el general José Quevedo. Entre ellos discutirían la pertinencia de entroncar la Panamericana y Tampico en la Congregación de "El Pujal", toda vez que en el primer proyecto se la hacía atravesar por caminos de Compañías Petro-

${ }^{25}$ CMLXXV, doc. 26361, 1936. CEHM-CARso, México. 
leras, terrenos pantanosos y lagunas estacionales que, seguramente lo obstruirían estacionalmente, lo que encarecería el proyecto y su conservación. Como alternativa, las autoridades y agentes locales propusieron que el trazo se dirigiera a ciudad Valles para emplear la infraestructura y balnearios que ya frecuentaban los pobladores circunvecinos y que también visitaban los tampiqueños por tren. Además, recordaron que la Secretaría de Comunicaciones proyectaba unir la ciudad de Valles con Tampico. ${ }^{26}$

El segundo ramal (167 kilómetros al noreste de la ciudad de México) era importante por densidad demográfica; podría conectar poblaciones de Hidalgo y el sur del Bajío a través de Querétaro. Al comenzar 1940, tenía 147 kilómetros casi totalmente "revestidos" (80\% del trazo total).

En el tercero convergieron intereses de Matamoros y su vecina Brownsville. En la primavera de 1939, comerciantes texanos encabezados por J. Wounter, presidente de su Cámara de Comercio, ofrecieron 50000 dólares para construirlo. La Secretaría de Obras Públicas les respondió que su "subsidio" no bastaba para iniciar la obra y les propusieron comprar bonos para todo el tramo (500 000 dólares). Bajo este supuesto la carretera quedaría lista rápidamente. Esta respuesta no arredró sus intenciones, pero expusieron su interés de cubrirse ante fluctuaciones por cambio de divisas y dificultades para retornar su capital. ${ }^{27}$

El naciente Departamento de Turismo propondría objetivos ambiciosos; intentó coordinar actividades de autoridades municipales. Las conminaría a conservar tradiciones, "pavimentar", crear jardines, introducir agua potable, alumbrado, etc. Además, les pedía información de ferias, "bellezas naturales", fiestas patrióticas y religiosas para promoverlas y también reglamentaba edificaciones para "armonizar estilos locales". ${ }^{28} \mathrm{Al}$ hacerlo inventó nuevos rostros en los "muchos Méxicos" que los autos y carreteras conectaban.

En el anhelo de conciliar el pasado con la modernidad, esta tenía mejores medios para publicitar las nuevas formas de vivir el turismo y eventos que lo gestaban. Los transmitiría por radio ${ }^{29}$ y "películas a colores". Con películas y numerosos reportajes fotográficos y periodísticos fue registrada la

${ }^{26}$ CMLXXV, docs. 26940 y 27390, 1936 y 1937. CEHM-CARso, México.

${ }^{27}$ CMLXxv, docs. 26940 y 33487, 1936 y 1937. CEHM-CARso, México.

28 CMLXxv, doc. 27417, 1936. CEHM-CARso, México.

${ }^{29}$ Como las ceremonias de inauguración con los presidentes mexicano y estadunidense que interesó a Pathe, Fox y Paramount. Funcionarios de la AMA y ARBA trabajaron para arreglar este tipo de pormenores del encuentro presidencial. 
inauguración de la Panamericana. William Furlong, director de la Asociación Interamericana de Autopistas (AIA), las exhibía como noticiarios y cortometrajes. Furlong potenciaría la representación de la AMA en San Antonio, Los Ángeles, Tucson, Chicago y Nueva York. ${ }^{30}$

El interés binacional en pro de las carreteras mexicanas era del todo palpable. En México y Estados Unidos florecían compañías y campañas que supervisaban alcances, logros y problemas del creciente flujo carretero. Ejemplo de ello fue el impulso propagandístico de los pasquines Mapa, The Monterrey Greeter y Hoteles. Los dos primeros eran órganos de la AMA. Mapa tenía un propósito amplio y brindaba información de la mayor parte de la red carretera nacional, mientras The Monterrey Greeter, sostenido por socios regionales, se concibió para ofrecer información turística a anglohablantes, enfatizando atractivos neoleoneses. El interés se multiplicó en periódicos de Texas, Mississippi, Chicago, Nueva Orleáns, etc. El lejano Boston Herald Sunday comisionó a Gerould para informar su experiencia al viajar por auto en la Panamericana. ${ }^{31}$

\section{CONCLUSIONES}

Pese a altibajos, el periodo de entreguerras fue crucial para la industria automotriz y el desarrollo de la red carretera mexicana. Tras su impulso subyacieron intereses de todo tipo, incluyendo afanes modernizadores del stablishment y, sobre todo, el deseo de responder pragmáticamente a la contracción económica del final de la década de los veinte. En la década de los treinta, un nuevo empuje carretero dinamizó a transportistas, hoteles, bancos, centros de recreo, etc. El empuje vino de numerosos esfuerzos de coordinaciones locales, estatales y binacionales, aunque no siempre fueron exitosos.

Esa segunda etapa también fue permeada por sentimientos panamericanistas. Fue un camino largo de 1924 a 1938, desde Washington hasta Santiago de Chile, iniciado semioficialmente por países interesados en la idea de construir una carretera Panamericana. El enorme desafío abría la posibilidad de que actores privados y funcionarios binacionales de muy diversos rangos

30 CMlxxv, doc. 32424, 1937. CEHM-cARso, México.

31 R. Gerould, "Adventures lurks in every turn of Mexican highway", The Boston Herald Sunday, 21 de febrero de 1937; "Jacala y Chapulhuacan en la carretera panamericana”, The Boston Herald Sunday, 28 de febrero de 1937. Recuperado de http://www.bostonherald.com/ 
colaboraran, aunque al faltar programas coherentes o al haber urgencias terribles, la construcción de carreteras siempre podía enredarse bajo políticas de corte inmediatista. Claro, el programa roosveltiano era más complejo, pero como sus Civilian Conservation Corps, sus programas carreteros también intentaban -ante todo- atender el grave problema social del desempleo. Al final, la política contracíclica de Roosevelt ayudó a Estados Unidos a salir de la recesión y a subsanar recelos en su política hacia Latinoamérica. Este marco ayudó comercialmente a México; los primeros signos vinieron con el acuerdo de la plata, que se ratificarían en la contención de boicots y en su neutralidad frente a la política expropiatoria de Cárdenas.

En estos escenarios, las actuaciones individuales tuvieron un peso relevante. Referimos el de Daniels para el "nuevo trato" y "buena vecindad" que disminuyeron presiones por repartos agrarios y la expropiación. La colaboración binacional de funcionarios facilitó trabajos carreteros. Faltaron muchos personajes, cuya actuación sería relevante, como Vicente Cortés Herrera, Ulises Irigoyen o el jefe del Buró de Caminos Públicos, Thomas MacDonald, quien inspeccionó obras en Jalisco y del "Camino Panamericano"; 32 asimismo, expresidentes y exministros empresarios que incursionaron en los atractivos negocios del turismo. Por cortedad del espacio centramos la atención al impredecible éxito del automóvil en México. Arrasó literalmente al ferrocarril, algo también debido a una política descoordinada y en los hechos ¿inconscientemente? antiferrocarrilera.

\section{LISTA DE REFERENCIAS}

Álvarez, I. (comp.) (2017). Automotores y transporte público. Un acercamiento desde los estudios históricos. México: El Colegio Mexiquense.

Anaya, L. (2013). Guerras, automóviles y carreteras. La influencia norteamericana y el mercado automotriz mexicano en la postrevolución mexicana. En Boletín FAPECYFT, 73.

${ }^{32}$ MacDonald reportaba al secretario de Estado, S. Welles. Cortés Herrera, subsecretario del ramo, era su enlace; su relevancia se confirmó al ser nombrado primer "Gerente General de la Administración del Petróleo". 
Armstrong, Ch. y Nelles, H. V. (1984). A curious capital flow. Canadian investment in Mexico, 1902-1910. The Business History Review, 58(2), 178-203. Dor: http://doi. org $/ 10.2307 / 3115047$

Azuela, M. (1985). Nueva burguesía. México: FCE (Lecturas Mexicanas, 75).

Beals, C. (1937). America South. Filadelfia yNueva York: JB Lippincott Company.

Bess, M. K. (2017). Routes of compromise. Building roads and shaping the nation in Mexico, 1917-1952. Lincoln y Londres: University of Nebraska Press.

Beltrán Juárez, J. F. (2015). La administración obrera de los Ferrocarriles Nacionales de México: estimaciones de los daños económicos y la opinión pública, 1938-1940. Cuernavaca: Facultad de Humanidades-Universidad Autónoma del Estado de Morelos.

Cárdenas, L. (1979). Palabras y documentos públicos 1928-1970 (3 vols.). México: Siglo XXI Editores.

Coatsworth, J. H. (1984). El impacto económico de los ferrocarriles en el porfiriato. Crecimiento contra desarrollo. México: Era.

Cooperativas (12 de junio de 1935). Diario de los Negocios. Finanzas y Comercio.

Department of Commerce (Herbert Hoover, Secretary) (1926). Commerce Yearbook 1925. Washington: Washington Government Office.

Department of Commerce (Herbert Hoover, Secretary) (1928). Commerce Yearbook 1927. Washington: Washington Government Office.

Department of Commerce (Herbert Hoover, Secretary) (1929). Commerce Yearbook 1928. Washington: Washington Government Office.

Freeman, B. (2010). Driving Pan-Americanism: The imagination of a Gulf of Mexico highway. The Journal of Latino-Latin American Studies, 3(4), 56-68. DoI:

https://doi.org/10.18085/llas.3.4.g380050082v17218

Friedlaender, A. (1969). The dilemma of freight transport regulation. Washington: The Brookings Institution Washington.

González, L. S. (1992). Proceso de configuración territorial de la industria automotriz terminal en México, 1964-1989. México: Universidad Autónoma del Estado de México.

Grunstein, A. (2008). Mariano Cabrera y Javier Sánchez Mejorada. Dos ejecutivos frente al problema laboral de los Ferrocarriles Nacionales de México, 1924-1935. Boletín FAPECYFT, 59.

Grunstein, A. (2012). Consolidados: José Yves Limantour y la formación de los Ferrocarriles Nacionales de México. México: Consejo Nacional para la Cultura y las Artes.

Hernández, M. L. (2001). Guadalupe Mainero. Vida y obra 1856-1901. México: Instituto Tamaulipeco para la Cultura y las Artes. 
Holt, S. (1923). The bureau of public roads. Its history, activities, and organization (Monograph 26). Brookings Institution, Institute for Government Research. Baltimore Maryland: The Johns Hopskins Press.

Kersaw, I. (2002). Hitler. Barcelona: Crítica.

Kuntz, S. y Riguzzi, P. (1996). El triunfo de la política sobre la técnica: ferrocarriles, Estado y economía en el México revolucionario. En S. Kuntz y P. Riguzzi (coords.), Ferrocarriles y vida económica en México (1850-1950). Del surgimiento tardío al decaimiento precoz. México: El Colegio Mexiquense/UAM-Xochimilco.

Lewis, T. (1997). Divided Highways. Buiding the Interestate Highways, Transfroming American Life. Estados Unidos: Viking Press.

McCloud, J. F. (2015). Del Jeep al Torino. La historia de IKA, primera planta automotriz integrada de Sudamérica. Carapachay: Lenguaje Claro Editora.

Moulton, H. (1933). The American transportation problem. Washington: The Brookings Institution.

Payró, M. (1999). Altas noticias. Septiembre 1.

Perkin, H. (1976). The Age of Automobile. Londres: Quartet Books.

Ripley, T. (2003). The Wehrmacht. The German army in World War II, 1939-1945. Nueva York y Londres: F. Dearborn.

Rose, M. (1979). Interestate. Express highway politics, 1941-1956. Kansas: Lawrence, The Regent Press.

Samstad, J. (1996). Sindicalismo y la reestructuración productiva. (Documento de Trabajo). Tijuana: El Colegio de la Frontera Norte.

Sánchez, G. A. (1997). La banda del automóvil gris. La ciudad de México, la revolución, el cine y el teatro. México: Sansores \& Aljure Editores.

Secretaría de Economía Nacional, Dirección General de Estadística (1940). Tercer censo industrial de los Estados Unidos Mexicanos. México: Secretaría de Economía Nacional.

Sousa, M. (1946). Sentido nacional y social de las obras públicas. En Seis años de actividad nacional (pp. 411-438). México: Secretaría de Gobernación/Talleres Gráficos de la Nación.

Valencia, A. (2015). El descarrilamiento de un sueño. Historia de los Ferrocarriles Nacionales de México, 1920-1949. México: Centro de Estudios Históricos-El Colegio de México.

Vera, A. (1943). La pesadilla ferrocarrilera. Guadalajara: Cía. Linotipográfica Guadalajara. 
Weingroff, R. F. (junio, 1996). Federal-Aid Highway Act of 1956: Creating the Interstate System. Public Roads, 60(1), 1-9. Recuperado de http://www.fhwa.dot.gov/ infrastructure/rw96e.cfm

Wik, R. (1972). Henry Ford and grass-roots America. Ann Arbor: University of Michigan Press.

\section{OTRAS FUENTES}

Archivos

APEC-FAPEcyft Archivo Plutarco Elías Calles-Fideicomiso Archivo Plutarco Elías Calles y Fernando Torreblanca, México.

Cenm-CArso Centro de Estudios Históricos de México-Carso, México. 